\title{
EESTI ASULANIMEDE TRANSKRIBEERIMISEST JA KÄÄNAMISEST VENE KEELES
}

\section{Oksana Palikova, Katrin Karu}

\begin{abstract}
Ülevaade. Artiklis käsitletakse probleemi, mis kerkib aeg-ajalt esile vene keelde tõlkijate ja vene keele toimetajate praktikas: kuidas tuleks sihtkeeles (vene keeles) kirjutada lähtekeele (eesti keele) pärisnimesid? Antud uurimuses keskendutakse ühe Eesti toponüümide rühma funktsioneerimisele vene keeles. Probleemi võib vaadelda kahest aspektist: kohanime transkribeerimine ja morfoloogiline vormistus. Transkribeerimisele on erialakirjanduses pööratud rohkem tähelepanu võrreldes kohanime morfoloogiaga. Viimase puhul lähtutakse pigem keelevaistust, mitte kindlatest reeglitest. Eesti asulanimede näitel vaadeldakse neid kahte aspekti lähemalt. Artikli lópus antakse praktilisi soovitusi kõige rohkearvulisema asulanimede rühma moodustavate $a$-lõpuliste nimede kirjutamiseks venekeelses tekstis.
\end{abstract}

Võtmesõnad: toponüümid, praktiline transkriptsioon, ümberkirjutusreeglid, morfoloogia, keelekorraldus

\section{Lähtealused}

Võõrnimede kirjutamisel tuleb tõlkijal otsustada, milline peab olema sõna graafiline vormistus sihtkeeles. Probleem tekib nende võõrnimede puhul, mille kirjapilt ei ole määratud traditsiooniga. Seetõttu on tõlkija jaoks oluline tunda praktilise transkriptsiooni reegleid.

\subsection{Praktiline transkriptsioon}

Praktilist transkriptsiooni tuleb eristada nii "tavalisest" transkriptsioonist, mille puhul toetutakse sõna foneetilisele vormile, kui ka translitereerimisest, mil antakse edasi sõna tähekuju. Praktilise transkriptsiooni jaoks on oluline sõna üldise (osaliselt ka graafilise) kuju säilitamine sihtkeeles (Гиляревский, Старостин 1985: 21). Seetõttu kasutatakse praktilises transkriptsioonis translitereerimise elemente. Just 
sellega on näiteks seletatav eestikeelsete pikkade häälikute märkimine vene keeles kahe tähe abil: uu yy, aa aa jne.

Eesti nimede praktilises transkriptsioonis vene keelde saab peamiselt toetuda kahele allikale:

1) "Vene-eesti ja eesti-vene ümberkirjutusreeglid" ning selle alajaotus "Eesti-vene tähetabel. (Emakeele Seltsi keeletoimkonna 23.11.1995 soovitus)" (Keeletoimkond 2000: 111-114). See reeglistik on ümbertöötatud variant 1973. a ilmunud brošüürist "Eesti pärisnimede kirjutamine vene keeles" (Eesti pärisnimed 1973). Lisaks on olemas tähetabel "Eesti nimede kirjutamine vene tähestikus", mille on kinnitanud Eesti haridus- ja teadusminister 2005. a. 2008. a aprillis toimus Eesti Keele Instituudis nõupidamine, kus arutati eesti kohanimede ümberkirjutusreeglite optimeerimist. Parandusettepanekud edastati Emakeele Seltsi keeletoimkonnale. 29.10.2008 võttis Emakeele Seltsi keeletoimkond vastu "Muudatused eesti-vene tähetabelis" (Keeletoimkond 2008). Haridus- ja teadusminister on 20.11.2008 tähetabeli muudatused kinnitanud (vt Riigiteataja 2008).

2) "Võõrnimed vene tekstis. Käsiraamat" (Гиляревский, Старостин 1985). Kuna eesti keelel, sarnaselt teiste liiduvabariikide keeltega, ei olnud Nõukogude Liidus võõrkeele staatust, siis R. Giljarevski ja B. Starostini teatmikus ei ole eesti nimede ümberkirjutusreegleid. Samas ei ole ka uuemaid venekeelseid allikaid, mis täidaksid seda lünka. Ent võrdluseks võib vaadelda, milliseid soovitusi antakse nimetatud teatmikus soome pärisnimede ümberkirjutamiseks vene keelde.

Ilmnes, et soome nimede ümberkirjutusreegleid ei saa kasutada eesti nimedes. Teatmikus on öeldud, et juba alates 1961. aastast eksisteerib nüüdseks välja kujunenud eesti kohanimede ümberkirjutamise traditsioon, mille kohaselt nt pikka $i$-d transkribeeritakse täheühendi uй abil (Гиляревский, Старостин 1985: 237), nt Iisaku - Ийзаку ${ }^{1}$ Samas soome perenime Nïtemaa puhul soovitatakse ümberkirjutamisel kasutada kahte $i$-d: Ниитемаa (samas: 236).

Teatmikust leiame ka sellise soovituse: "[Soome] kohanimede ümberkirjutamisel kaotatakse topelttäht, isikunimede puhul see säilitatakse" (samas: 237) ning edasi: “ent ee, yy, ää, öö puhul kasutatakse vene keeles ühekordset tähte” (samas: 238).

Eesti (koha)nimede puhul on vene keeles alati kehtinud teistsugune reegel. Vrd: - kaashääliku järel (Муствеэ) ning sõna alguses (Ээрику); ӥü (Кюйни); ää - $\quad$ sõna keskel või lõpus (Отепяэ), $\quad$ sõna alguses (Ээрма);

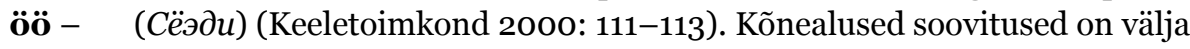
töötatud orienteerudes sõna foneetilisele (mitte graafilisele) kujule.

\subsection{Morfoloogiline vormistus}

Kuna vene keel on valdavalt flekteeriv, arenenud deklinatsiooniga, siis püütakse võõrpäritolu sõna integreerida oma grammatilisse süsteemi. Seetõttu kuulub iga laenatud nimisõna sõltuvalt selle lõpuhäälikust vene keeles ühte kolmest käändkonnast ning sellele omistatakse kõik vastava käändkonna muutelõpud. NtЛондон (London) - I käändkond, Куба (Kuuba) - II käändkond jne. 
Samas eksisteerib rida piiranguid, mis takistavad laenatud pärisnimede käänamist. Nii näiteks ei käänata ühesilbilisi võõrpäritolu nimesid, samuti selliseid nimesid, mille lõputähtedeks on -o, $-e,-u$ (Суперанская 1965: 118). Mis puudutab mitmesilbilisi $a$-lõpulisi rõhuta lõpuga võõrnimesid, siis neid "e n a m a s t i [O.P., K.K. sõrendus] käänatakse nagu II käändkonna nimisõnu, sõltumata grammatilisest soost. Sama kehtib sõnade kohta, mille lõpus on - või - . Kui sõnad on ühesilbilised või nimetava lõpus on teine täishäälik, siis neid ei käänata." (Гиляревский, Старостин 1985: 45)

\subsection{Keelelise korrektsuse kriteeriumid}

Võõrnime transkribeerimise ja morfoloogilise vormistuse seisukohalt võib pidada määravaks kolme järgmist kriteeriumi. Esimesed kaks lähtuvad vormist, viimane on tähenduslik.

1) “Transkribeeritud sõna peab olema äratuntav" (Суперанская 1978: 125). Oluline on püüelda selle poole, et tõlketeksti lugeja viiks tekstis kasutatud nimega vastavusse sama objekti (nt asula), mis originaalteksti lugeja.

2) Transkribeeritud sõna peab olema adekvaatselt retranskribeeritav (Суперанская 1978: 126-127). Sõltumata võõrnime vormistusest, peab olema võimalik maksimaalselt täpne tagasipöördumine lähtekeele graafilise kuju juurde.

3) Ümberkirjutamisel tuleb püüelda selle poole, et säiliksid võõrnime tähenduslikud elemendid (Суперанская 1978: 69). Ehk teisisõnu: kui võõrnimi sisaldab elemente, millel on lähtekeeles olemas tähendus, siis peab nimi olema transkribeeritud nii, et selle struktuur oleks maksimaalses vastavuses lähtekeele nime struktuuriga: “.. võõrnimede foneetilise vormi säilitamine ei tohi olla eesmärgiks omaette. Transkribeerimise käigus on kõige olulisem säilitada ümberkirjutatavas sõnas sisalduv info." (Суперанская 1978: 152)

\section{Eesti asulanimede transkriptsioonist ja morfoloogilisest vormistusest vene keeles}

Vaatleme lähemalt Eesti asulanimesid. Seejuures keskendume nende lõputähtede transkribeerimise võimalustele ning muutemorfoloogilistele omadustele ning sellest tulenevalt ka käänamisvõimalustele.

\subsection{Eesti asulanimede praktiline transkriptsioon}

\subsubsection{Pikad täishäälikud}

Et eesti asulanimedes esineb pikki lõpuvokaale, mida graafiliselt tähistavad topelttähed, kerkib esile küsimus, mismoodi tuleks need vene keelde ümber kirjutada. Üldiselt võib kõnealuse olukorra liigitada nende juhtumite hulka, mil ühe keele mitmele keeleühikule vastab teises keeles kaks või isegi üks keeleühik (Суперанская 
1978: 131). Huvitav on märkida, et Aleksandra Superanskaja illustreerib kõnealust juhtu eesti keele näitel: "eesti lühikestele, pikkadele ja ülipikkadele vokaalidele vastavad vene keeles "keskmised", mis fonemaatiliselt ei eristu kui pikad ja lühikesed." (Суперанская 1978: 131)

Vokaali pikkuse märkimine topelttähtede abil on vastavuses retranskriptsiooni nõudega, ent taoline retranskriptsioon ei ole ilmne ettevalmistamata kasutaja jaoks, vrd: $\ddot{\boldsymbol{u}} \ddot{\boldsymbol{u}}=$ юй, $\ddot{\boldsymbol{o}} \ddot{\boldsymbol{o}}=\ddot{e} \ni, \ddot{\boldsymbol{a}} \ddot{\boldsymbol{a}}=$ яэ / ээ, $\boldsymbol{e} \boldsymbol{e}=$ өэ / ээ. Kusjuures see puudutab ka neid juhtumeid, mil esineb täielik graafiline kokkulangevus kahes keeles: $\boldsymbol{a \boldsymbol { a }}-a a$,

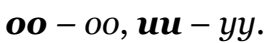

Vene keeles tähendab topelttähtede kasutamine neist kummagi eraldi hääldamist (vrd зоопарк 'loomaaed', воочию 'oma silmaga')2, seetõttu tuleks eesti pikkade ja ülipikkade vokaalide ümberkirjutamise reeglid vene keeles topelttähtede või tähekombinatsioonide abil samuti formuleerida eraldi. Nt Emakeele Seltsi keeletoimkonna soovitustes on selgelt sõnastatud vaid kolme topelttähe ümberkirjutamise reeglid. Need on ää (2 varianti), öö ja üü. Teiste topelttäishäälikute ümberkirjutamise reeglid sisalduvad implitsiitselt näidetes, kuid ei ole eraldi sõnastatud, samas vene keele seisukohalt on see hädavajalik:

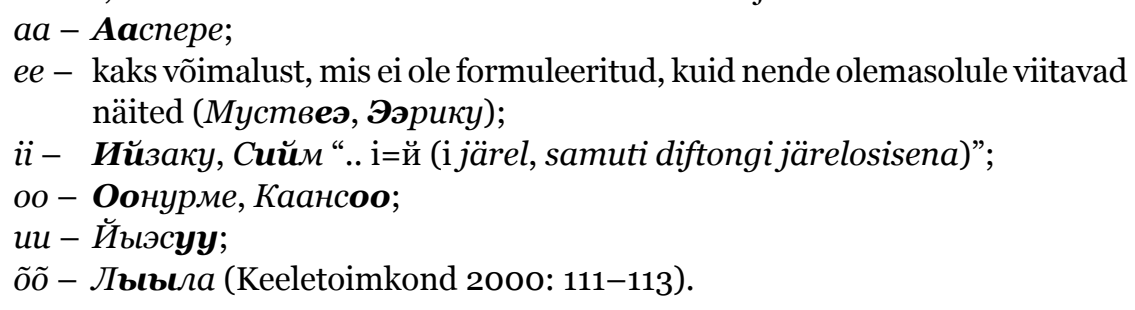

Mitte mingil juhul ei tohi lubada eesti (või soome) topeltvokaalide ümberkirjutamisel vene keelde ühe tähe kasutamist, sest üksiktähe kasutamine topelttähtede asemel võib viia olulise infokaoni lähtekeele sõna tähendusliku struktuuri osas. Topelttähtede kasutamine ümberkirjutamisel "aitab kaasa retranskriptsioonile ning nime infostruktuuri säilimisele” (Суперанская 1978: 196-197). Vrd: Põltsamaa, Virumaa - Võhma, Matjama.

Seega Eesti (asula)nimede ümberkirjutamise optimaalne moodus on ühest küljest olemasolevate ümberkirjutusreeglite kasutamine (need vajavad siiski täiendamist), teisest küljest - ümberkirjutamine koos originaalnimede äratoomisega (eriti dokumentides ja ametlikes tekstides).

\subsubsection{Veel kord Tallinnast}

Kui ülaltoodud näited, mis illustreerivad topeltvokaalide ümberkirjutamist, ei tekita üldiselt vastuväiteid, siis küsimus sellest, kuidas tuleks vene keeles kirjutada Eesti pealinna nime, on juba muutunud traditsiooniliseks. Püüame siinkohal abstraheerida probleemi keelevälisest küljest ning vaatleme lingvistilisi argumente.

Üks vastuväide, et Tallinn (Таллинн) tuleks vene keeles kirjutada kahe $n$-iga, seisneb selles, et vene keeles ei ole võimalik hääldada pikalt sõna lõpukonsonanti. Ent nii nagu topeltvokaalid, nõnda ka topeltkonsonandid "muutuvad vene keelde ümberkirjutamisel lihtsalt t o p e l t $\mathrm{t}$ ä h t e d e k s, millel puudub morfoloogiline või ortograafilinefunktsioon, kuid millel on tähtis roll sõ $\mathrm{n}$ a de ja nende 
v o r m i d e e r i s t a m i s e l." [O.P., K.K. sõrendus] (Суперанская 1978: 214). Ehk teisisõnu: topeltkonsonandi kirjutamine vene keeles ei tingi selle pikka häl̈ldust. Nt sõnades финн 'soomlane', мусс 'mannavaht', В. Скотm (V. Scott), Стокманн (Stockmann) jms topeltkonsonante e i h ä äld a t a pikalt.

A. Superanskaja märgib, et vene keelele on omane tendents hääldada pikalt konsonante, mis asuvad vokaalide vahel pärast rõhulist silpi (samas: 215), ehk sellises positsioonis nagu $l$ sõnas Tallinn. Veelgi enam: sellises positsioonis võib pikalt hääldada ka ühekordset konsonanti, nt Гавана (Havanna), драма 'draama' (Суперанская 1978: 215). Seejuures toetub uurija A. Reformatski arvamusele, kes samuti märkis, et foneetilistel argumentidel topeltkonsonantide kirjutamise kasuks vene keeles ei ole piisavat alust (samas: 215). Niisiis, topeltkonsonandi kirjutamine sõna Tallinn (Таллинн) lõpus ei tekita vastuolu sõna graafilise ja foneetilise kuju vahel.

Teisest küljest eksisteerib nõue, et arvestada tuleb võõrpäritolu nime struktuuri. See tähendab, et sõna tähenduslikud komponendid peavad lähte- ja sihtkeeles kokku langema, nt sellised struktuurselt erinevad nimed nagu Bergson ja Bergsson, Janson ja Jansson, milles "kaashäälikurühma ühe komponendi ärajätmine muudaks sõnade eristamise võimatuks" (Суперанская 1978: 127). Kuna eesti keeles ei ole peale Tallinna linnanimesid, mille struktuuri kuuluks sõnaosa linn, siis võib tunduda, et see probleem polegi oluline. Kuid on terve rida linnaosade nimetusi, mis sisaldavad sama komponenti ning mille lõpus kirjutatakse topelt $-n$. Sellise kirjapildi aktsepteerimine vene keeles ei ole kunagi tekitanud kahtlusi ega vaidlusi. Vrd nt Tartu linnaosade nimesid: Annelinn - Аннелинн, Taтmelinn таммелинн, Supilinn - Супилинн.

Kõige tugevamaks ja võib-olla ainsaks argumendiks selle vastu, et kirjutada sõna Tallinn (Таллинн) lõppu topeltkonsonant, on traditsiooni arvestamise nõue, kuivõrd pikka aega kirjutati seda sõna tõepoolest ühe $n$-iga. Traditsioon ongi peamiseks põhjuseks, miks ei saa kõikide võõrpäritolu nimede kirjutamist allutada ühtsetele reeglitele. Samas, vaatamata uutele reeglitele, mille kohaselt venekeelses tekstis ei tohi $l$-i järel, millele omakorda järgneb konsonant, kasutada pehmendusmärki, säilib siiski tuntud isikute perekonnanimede traditsiooniline kirjutusviis: Вильде, Крейцвальд (Keeletoimkond 2000, 2008). Teisest küljest on traditsiooni muutmine õigustatud, kui see tingib lähtekeele sõna struktuuri taastamise ega muuda olulisel määral nime graafilist ja foneetilist kuju. Seejuures on lihtsam unifitseerida selliste sõnade kirjutamist, kus muutused on väikesed ega puuduta sõna algust, nt Ливерпуль Ливерпул (Liverpool), Лос-Анджелос Лос-Анджелес (Los Angeles) (Суперанская 1978: 155).

Lõpetuseks võiks lisada, et aastate jooksul, mis on möödunud hetkest, kui hakkas kehtima nõue kirjutada Таллинн kahe $n$-iga, on vähemalt osal vene keelt kõnelevast elanikkonnast jõudnud välja kujuneda uus traditsioon - kirjutada Eesti pealinna nime lõppu topeltkonsonant. Seda toetavad ka koolinõuded, mis on iseenesest tugev argument. 


\subsection{Eesti asulanimede käänamisest}

\subsubsection{Eesti asulanimed Iõpuhäälikute seisukohalt}

Statistikaameti andmetel on Eestis 2008. a veebruari seisuga 4670 asulat (linnad, külad, alevid, alevikud). Kasutades statistikapaketti SPSS analüüsime neid lõpuhäälikute seisukohalt. Selgus, et Eesti asulanimede hulgas:

1) leidub vaid üks konsonantlõpuline nimi (Tallinn);

2) ei ole $\ddot{u}$ - ja $\ddot{o}$-lõpulisi asulanimesid;

3) on väga harvad lõpuvokaalid y (0,2 \%), õ (0,5 \%), $\ddot{a}$ (o,8 \%), o (1,6 \%);

4) on umbes ühepalju $u$ - ja $i$-lõpulisi asulanimesid, vastavalt $14,1 \%$ ja $15,4 \%$

5) esinevad kõige sagedamini lõpuvokaalid $e$ (25,9 \%) ja $a(41,5 \%)$.

Analüüsi tulemused on koondatud tabelisse 1.

Tabel 1. Eesti asulanimede lõputähed ja nende esinemissagedus

\begin{tabular}{|l|c|c|l|}
\hline Lõputäht & Sagedus & Protsent & \multicolumn{1}{|c|}{ Näited } \\
\hline$a$ & 1936 & $41,5 \%$ & Lehola, Tuulna \\
\hline$e$ & 1211 & $25,9 \%$ & Naage, Kose \\
\hline$i$ & 717 & $15,4 \%$ & Vansi, Heigi \\
\hline$u$ & 658 & $14,1 \%$ & Sõmeru, Maeru \\
\hline$o$ & 76 & $1,6 \%$ & Piissoo, Loo \\
\hline$\ddot{a}$ & 38 & $0,8 \%$ & Lüütsepä, Küllätüvä \\
\hline$\tilde{o}$ & 22 & $0,5 \%$ & Ignasõ, Kitsõ \\
\hline$y$ & 11 & $0,2 \%$ & Borrby, Saxby \\
\hline$n$ & 1 & $0,0 \%$ & Tallinn \\
\hline Kokku & $\mathbf{4 6 7 0}$ & $\mathbf{1 0 0 , 0} \%$ & \\
\hline
\end{tabular}

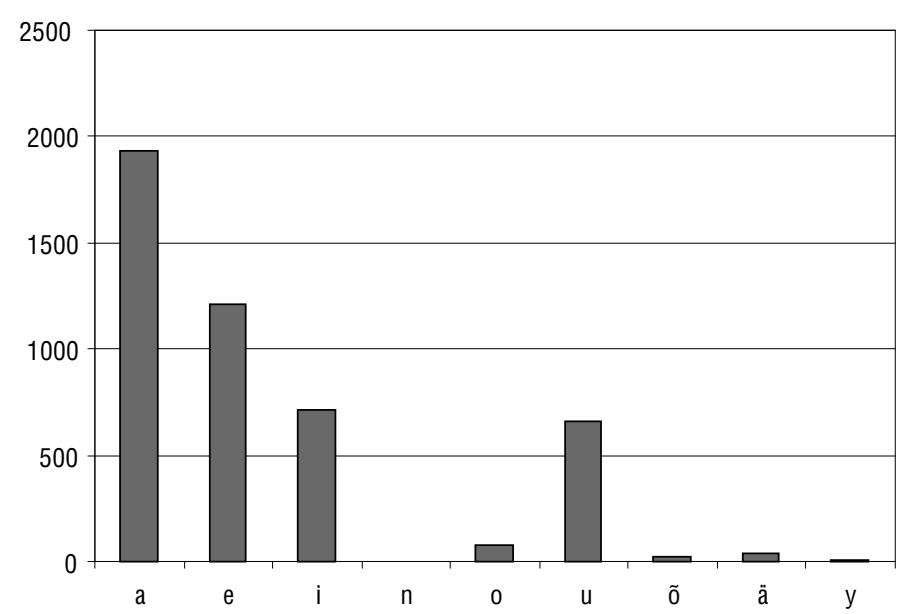

Joonis 1. Lõpuvokaali esinemissagedus Eesti asulanimedes

Vene keele seisukohalt on sõna käänamise probleem relevantne vaid konsonant202

lõpuliste nimede puhul või kahe- ja enamasilbiliste $a$-lõpuliste rõhuta lõpuga 
nimede puhul. Seega huvitavad meid olemasolevatest asulanimedest vaid $a$ - ja $\ddot{a}$-lõpulised. Kuna ää transkribeeritakse kui -яэ, siis sellise lõpuga sõna satub vene keeles muutumatute sõnade hulka. $a a$-lõpulist sõna ei saa samuti käänata, sest taoline sõnalõpp ei ole vene keelele omane, järelikult on ka sellised asulanimed vene keele seisukohalt muutumatud sõnad. Järgnev graafik illustreerib asjaolu, et just $a$-lõpulised asulanimed moodustavad lõviosa kõigist Eesti asulanimedest.

\subsubsection{Kas vene keeles tuleb käänata a-lõpulisi asulanimesid?}

Vaatamata sellele, et vene keele süsteem justkui nõuaks $a$-lõpuliste nimisõnade käänamist, omistades neile II käändkonna muutelõppe, ei ole see reegel absoluutne. Sageli tekitab vastuväiteid $a$ - või $\Omega$-lõpuliste gruusia, jaapani jm perenimede käänamine: "Lõputähtede $a$ või $\Omega$ mõtestamine nominatiivi lõpuna ja sellest tulenev isikunimede käänamine (nt Окуджавы (genitiiv) [Okudžavat], Куросаве (daativ) [Kurosavale], Данелией (instrumentaal) [Danelijaga]) tekitab vastuväiteid nende hulgas, kes peavad sellist morfeemjaotust valeks ning liigitavad taolisi nimesid muutumatuteks sõnadeks (беседовал с Гулия ['rääkis Gulijaga'])" (Ермолович 2001: 28). ${ }^{3}$

Kui kohanimi esineb koos liiginimega, on vene keelele omane käänata mõlemat: nt в городе Серпухове 'Serpuhhovi linnas' (Гиляревский, Старостин 1985: 47). Samas meediatekstide jaoks on iseloomulik mitte käänata võõrpäritolu kohanime, käänates vaid liiginime: из города Плейнс 'Pleinsi linnast', в порту Эгвекинот 'Egvekinoti sadamas') (Гиляревский, Старостин 1985: 47). Sama tendents on täheldatav ka vene päritolu kohanimede puhul "tekstides, kus kajastatakse sõjatemaatikat, nt kõrgema ülemjuhatuse teadetes: Армия Тормасова была послана .. к селу Доброе ['Tormasovi armee saadeti Dobroje küla juurde']”. A. Superanskaja toob analoogseid näiteid, kus ei käänata $a$-lópulisi kohanimesid, nt из городов Кодза и Кинован 'Kodza ja Kinovani linnadest'; из индийского города Симла 'India linnast Shimla' jms. Loetlemata kõiki näiteid võib öelda, et need on üldistatavad kui tendents säilitada lähte- ja sihtkeele nimede identsus (Суперанская 1965: 137-139).

Teisest küljest on vene keelele omane "mitte käänata võõrpäritolu kohanimesid isegi siis, kui nende lõpud ei välista käänamist" (Суперанская 1965: 119). Seetõttu sageli ei käänata võõrpäritolu $a$-lõpulisi kohanimesid, kuigi keelesüsteem justkui nõuaks nende käänamist:4 “.. приехать к нам .. в Кочкор-Ата .. На северной оконечности Пегу-йома (Чжу Чжи-хэ).” 'tulla meile .. Kotškor-Atasse .. Pegu Yoma põhjatipus' (Суперанская 1965: 135).

Vaatleme mõnda interneti näidet: ${ }^{5}$

(1) БАДАЛОНА: Матчем в

ЦСКА начинает второй круг ТОП-16 Евролиги.

Что касается самой , то этот город располагается неподалеку от Барселоны на левом берегу небольшой речки Besos и Средиземного моря.

\footnotetext{
3 Sama probleemi kohta vt ka (Калакуцкая 1984: 62-97).

4 Teatud sõnarühmade mittekäänamise tendentsist, mis tekkis 19. saj ja on muutunud tugevamaks 20. saj, eriti selle teisel poolel, on räägitud vastses uuringus, kus käsitletakse tänapäeva vene keele aktiivseid protsesse (Гловинская 2008 227-239).

5 Kõik interneti näited on saadud lihtotsingu tulemusena 2008. a aprillis. Kasutati otsingumootorit Google. Otsiti a-lõpulisi asulanimesid, allikana kasutati maailma atlast (Сергеева, Антонов 1990). Eesmärgiks oli kontrollida reaalset keelekasutust kinnitamaks või ümber lükkamaks hüpoteesi selle kohta, et vene keeles kiputakse neid mitte käänama.
} 
(2) ФульдА: В же находится резиденция епископа - главы епископата

(3) АСАХИГАВА: - Что дальше делать будете, Рэйко? - В х хочу поехать.

Естественно ведь, с таким трудом пришла наконец в себя, и ехать в , чушь какая-то.

(4) КОУВОЛА: Туры в . Отели . Найти отель в -

(5) ХЮВИНКЯ: Впервые с Финляндией, ее природой, жизненным укладом, Ахматова познакомилась в 1915 году, когда оказалась в под Хельсинки.

(6) ЮВЯСКЮЛЯ: Только что вернулись в Питер из В много зелени - прямо с главной улицы можно попасть в настоящий лес, в центре которого - на вершине горы - находится стадион.

(7) ЯМСЯ: В ближайшем городе (Jämsä) предлагается посетить ресторан гостиницы “ ".

Isegi toodud näidetest ilmneb, et

a) suhteliselt "lihtne" on vene keelt emakeelena kõneleja jaoks käänata $a$-lõpulisi hispaania ja itaalia päritolu kohanimesid (nt Бандалона);

b) sama kehtib ka jaapani ja soome päritolu kohanimede kohta, ent kuna nendel on teisi võõrpäritolu sõna tunnuseid (vene keelele mitteomased häälikuühendid, nt hiaatus Kouvola), võivad nad tekstis esineda kui muutumatud sõnad: поехать в Асахигава 'sõita Asahigavasse', туры в Коувла 'ringreisid Kouvolas';

c) ei käänata $я$-lõpulisi [-’a] kohanimesid. See võib tuleneda asjaolust, et nt prepositsionaali lõpp - $e$ takistab sõna algvormi taastamist, vrd: ${ }^{?} 8$ Ямce $=$ Ямся või $Я_{\text {мса. }}$.

\subsubsection{Eesti a-lõpuliste asulanimede käänamisest vene keeles}

Vene keeles ei saa käänata ühesilbilisi asulanimesid ( $A a$ küla), samuti topeltvokaaliga lõppevaid asulanimesid (Põltsamaa).

Teiste Eesti $a$-lõpuliste asulanimede käänamine võib kaasa tuua ebasoovitava homonüümia, mis takistab retranskribeerimist. Iga $a$-lõpuline asulanimi võib obliikvakäänetes olla identifitseeritav kui $e$-või $u$-lõpuline. Nt on olemas kaks asulanime, mis erinevad teineteisest vaid lõpuvokaali poolest: Langa küla ja Lange küla. On arusaadav, et nime Langa käänamine vene keeles võib põhjustada nende kahe kohanime mitteeristamise ning lähte- ja sihtkeelse nime identsuse kao.

Eesti $a$-lõpuliste kohanimede käänamine võib tingida nende struktuuriinfo (morfeemiinfo) kao. Nt kui kohanimedes Laimetsa, Laimjala, Laiusevälja, Laaneotsa on lõpuvokaal obliikvakäände tunnuseks, siis nende sõnade käänamine sihtkeeles põhjustab olulise infokao, vrd: 8 ? Лайметсе 'Laimetsas', из ?Лаанеотсь 
Ülalöeldu ei kehti vaid ühe asulanimede rühma kohta. Tegemist on sõnadega, mis on vene keeles kohanenud, nn vanade laenudega. Ent nende hulka võib arvata vaid vähesed linnade nimed (laenude kohanemise põhjustel me siinkohal ei peatu): Elva, Narva, Valga.

Seejuures tuleks ära märkida, et käänamine on kohustuslik vaid toponüümi Narva (Нарва) jaoks, teiste nimede puhul on lubatud nii sõna algvormi kasutamine kui käänamine. Ülejäänud Eesti linnade nimede käänamine ei tundu otstarbekas.

Lõpetuseks võiks anda mõned soovitused eesti $a$-lõpuliste asulanimede käänamise kohta vene keeles.

1) Vene keeles võib käänata kohanenud $a$-lõpulisi asulanimesid nagu uз Нарвы 'Narvast', в Эльву 'Elvasse', рядом с Валгой 'Valga lähistel' jne.

2) Ülejäänud $a$-lõpulised asulanimed venekeelses tekstis ei käändu: noexamь в Йыгева 'sõita Jõgevale', рядом с Тапа 'Tapa lähistel', приехать из Рапла 'tulla Raplast' jne.

3) Dokumentides tuleks asulanimele lisada lähtekeele kirjapilt (see puudutab eriti külasid, aleveid ja alevikke): житель Ряэса (Rääsa) 'Rääsa elanik', сведения о Саувялья (Sauvälja) 'andmed Sauvälja kohta' jne.

4) Dokumentides tuleks asulanimedele võimalusel lisada liiginimi (ka see kehtib ennekõike külade, alevite ja alevike kohta):жители деревни Паэкюла (Paeküla) 'Paeküla küla elanikud', дом в деревне Оэла (Oela) 'maja Oela külas'.

\section{Kokkuvõte}

Võõrnime praktilise transkriptsiooni puhul kehtib kaks peamist reeglit: 1) võõrnime peab saama adekvaatselt retranskribeerida; 2) tuleb püüelda selle poole, et ümberkirjutamisel säiliksid võõrnime tähenduslikud elemendid. Järgides neid reegleid ning lähtudes eesti ja vene keelesüsteemide iseärasustest (nii graafilistest ja foneetilistest kui ka morfoloogilistest), tuleb Eesti asulanimede ümberkirjutamisel vene keelde arvestada järgmist:

1) vene graafiliste vahendite abil ümber kirjutada topeltvokaalid ja -konsonandid (Eesti pealinna nimi ei ole erandiks);

2) vene keeles tuleb vältida võõrpäritolu asulanimede käänamist. Ametlikes dokumentides on otstarbekas asulanimele lisada liiginimi ning sõna originaalne tähekuju.

\section{Viidatud kirjandus}

Eesti pärisnimed 1973 = Eesti pärisnimede kirjutamine vene keeles. Русская транскрипция эстонских имен собственных. Eesti NSV Teaduste Akadeemia Keele ja Kirjanduse Instituut. Tallinn: Valgus, 1973.

Ермолович, Дмитрий 2001. Имена собственные на стыке языков и культур. Москва: Р. Валент.

Гиляревский, Руджеро; Старостин, Борис 1985. Иностранные имена и названия в русском тексте. Справочник. Москва: Высшая школа.

Гловинская, Марина 2008. Активные процессы в грамматике. - Л. П. Крысин (ред.). Современный русский язык: Активные процессы на рубеже XX-XXI веков. Москва: Языки славянских культур, 187-270. 
Калакуцкая, Лариса 1984. Склонение фамилий и личных имен в русском литературном языке. Москва: Наука.

Keeletoimkond 2000 = Vene-eesti ja eesti-vene ümberkirjutusreeglid. - Kirjakeele teataja II. 1993-2000. Emakeele Seltsi keeletoimkonna soovitused. Tallinn: Emakeele Selts, 106-114

Keeletoimkond 2008 = Muudatused eesti-vene tähetabelis. Emakeele Seltsi keeletoimkonna otsus (29.10.2008). http://www.emakeeleselts.ee/otsused/eskt_otsus_2008_ttab. pdf (07.02.2009).

Riigiteataja 2008 = Kohanimede transkribeerimist ja translitereerimist reeglistava tähetabeli kehtestamine. - Haridus- ja teadusministri 20. novembri 2008. a määrus nr 64 . https://www.riigiteataja.ee/ert/act.jsp?id=13073380 (o7.02.2009).

Сергеева, С. И.; Антонов, В. М. (ред.) 1990. Атлас мира. Москва: ГУГК.

Суперанская, Александра 1965. Склонение собственных имен в современном русском языке. - Орфография собственных имен. Москва: Наука.

Суперанская, Александра 1978. Теоретические основы практической транскрипции. Москва: Наука.

Tamm, Johan 1961. Juhiseid eesti pärisnimede kirjutamise kohta vene keeles. - Johan Tamm. Eesti-vene sõnaraamat. Tallinn: Eesti Riiklik Kirjastus, 749-750.

Oksana Palikova (Tartu Ülikool) peamised uurimisvaldkonnad on kakskeelne leksikograafia, semantika, leksikoloogia.

oksana.palikova@ut.ee

Katrin Karu (Tartu Ülikool) peamised uurimisvaldkonnad on funktsionaalne grammatika, eesti ja vene keele kõrvutav grammatika ning mööndkonstruktsioonid.

katrin.karu@ut.ee 


\section{ON THE TRANSCRIPTION AND DECLENSION \\ OF THE ESTONIAN TOPONYMS IN RUSSIAN}

\section{Oksana Palikova, Katrin Karu}

University of Tartu

The article discusses a practical problem faced by interpreters and editors: how should Estonian toponyms be handled in the Russian language. The authors regard this problem from two points of view. In the first place, the problems of transcription are analyzed - in particular the requirements of practical transcription. Secondly, the morphological structure and declension of the Estonian toponyms are scrutinized.

As it turned out, nearly half (41.5\%) of all Estonian place-names end in - $a$, like nouns of the Russian second declension. In accordance with the general rules of the Russian language the nouns with the ending $-a$ are declined. However, taking into account various other factors, the authors of the given article make the conclusion that only those few names of towns which are old loans should be declined in Russian. Recommendations are given for using the names of Estonian settlements in Russian written texts.

Keywords: toponymy, practical transcription, morphology, language planning 